\title{
Preparation and Characterization of Antioxidant Nanoparticles Composed of Chitosan and Fucoidan for Antibiotics Delivery
}

\section{Yi-Cheng Huang * and Rou-Ying Li}

Department of Food Science, College of Life Science, National Taiwan Ocean University, 2 Pei Ning Road, Keelung 20224, Taiwan; E-Mail: d91548006@ntu.edu.tw

* Author to whom correspondence should be addressed; E-Mail: ychuang@mail.ntou.edu.tw; Tel.: +886-2-2462-2192 (ext. 5119); Fax: +886-2-2463-4203.

Received: 6 May 2014; in revised form: 16 July 2014 / Accepted: 16 July 2014 /

Published: 31 July 2014

\begin{abstract}
In this study, we developed novel chitosan/fucoidan nanoparticles (CS/F NPs) using a simple polyelectrolyte self-assembly method and evaluated their potential to be antioxidant carriers. As the $\mathrm{CS} / \mathrm{F}$ weight ratio was $5 / 1$, the $\mathrm{CS} / \mathrm{F}$ NPs were spherical and exhibited diameters of approximately $230-250 \mathrm{~nm}$, as demonstrated by TEM. These CS/F NPs maintained compactness and stability for 25 day in phosphate-buffered saline ( $\mathrm{pH}$ 6.0-7.4). The CS/F NPs exhibited highly potent antioxidant effects by scavenging 1,1-diphenyl-2-picrylhydrazyl (DPPH), reducing the concentration of intracellular reactive oxygen species (ROS) and superoxide anion $\left(\mathrm{O}_{2}{ }^{-}\right)$in stimulated macrophages. The DPPH scavenging effect of CS/F NPs primarily derives from fucoidan. Furthermore, these CS/F NPs activated no host immune cells into inflammation-mediated cytotoxic conditions induced by IL- 6 production and NO generation. The MTT cell viability assay revealed an absence of toxicity in A549 cells after exposure to the formulations containing $0.375 \mathrm{mg}$ $\mathrm{NPs} / \mathrm{mL}$ to $3 \mathrm{mg} \mathrm{NPs} / \mathrm{mL}$. Gentamicin (GM), an antibiotic, was used as a model drug for an in vitro releasing test. The CS/F NPs controlled the release of GM for up to $72 \mathrm{~h}$, with $99 \%$ of release. The antioxidant CS/F NPs prepared in this study could thus be effective in delivering antibiotics to the lungs, particularly for airway inflammatory diseases.
\end{abstract}

Keywords: chitosan; fucoidan; nanoparticle; antioxidant; antibiotic; delivery 


\section{Introduction}

Pulmonary delivery systems using particulate drug carriers are an attractive modality for treating airway disorders such as cystic fibrosis [1], asthma [2], pulmonary infections [3], pulmonary hypertension [4], and lung cancers [5]. Pulmonary delivery involves providing a direct and local delivery to the lungs, thus achieving both a selective pulmonary effect and a reduction of side effects. Alternatively, pulmonary drug delivery can be achieved by targeting the alveolar region where the drug can be absorbed through a thin layer ( 0.1 to $0.5 \mu \mathrm{m}$ thick) of epithelial cells and into the systemic metabolism. This causes enhanced permeability, absence of first-pass metabolism, rapid onset of action, and high bioavailability [6,7]. Therefore, pulmonary drug delivery serves as a means of delivering drugs either systemically or locally and has drawn increasing attention [8].

To achieve efficient pulmonary drug delivery, particulate drug formulation that delivers therapeutic agents to the site of action for lung diseases is necessary [7]. Nanoparticles (NPs) have recently been proposed as valuable carriers for efficiently transporting drugs to the lung epithelium without mucociliary clearance and phagocytic mechanisms [9,10]. Recent and rapid advances in nanotechnology and materials science have resulted in the development of numerous polymers that can be formulated into particulate drug carriers for efficient drug delivery [11,12]. Liposomes that can manipulate release, and target by altering bilayer constituents, have been used in various delivery systems [13]. However, cationic liposomes widely used for gene delivery have been observed to induce oxygen radical-mediated pulmonary toxicity [14]. Biodegradable polyester nanoparticles, such as poly(lactic-co-glycolic acid) (PLGA), have been widely used as delivery vehicles for various drugs and biopharmaceuticals [15,16]. However, PLGA hydrolytically degrades into acid components that are known to induce inflammatory responses [17]. The intratracheal treatment of PLGA microparticles provokes inflammatory responses, evidenced by a large recruitment of white blood cells to the lungs [18]. Therefore, developing novel antioxidant nanoparticles as pulmonary delivery carriers is necessary.

We recently developed chitosan/fucoidan (CS/F) NPs as carriers for drug delivery systems [19,20]. Fucoidan (F), which is extracted from brown seaweed, is a sulfated polyfucose polysaccharide $[21,22]$. Fucoidan demonstrates significant antioxidant and anti-inflammatory activities, and has received increasing interest in the field of biotechnology $[23,24]$. Rocha de Souza et al. reported that fucoidan obtained from Fucus vesiculosus has an inhibitory effect on the formation of hydroxyl radicals and superoxide radicals [25]. Mekabu fucoidan can relieve pulmonary inflammation and downregulate Th2-dominated responses, which might be useful for treating allergic inflammation [26]. Chitosan (CS), a cationic polysaccharide derived from chitin by alkaline deacetylation, is widely used as a carrier to improve and control the release of drugs [27,28]. In addition to being biocompatible and biodegradable by pulmonary lysozyme [29], CS is mucoadhesive [30] and can promote macromolecule permeation through well-organized epithelia [31-33]. CS/tripolyphosphate NPs have demonstrated an excellent capacity for protein entrapment and peptide absorption improvement by using several mucosal routes, such as the nasal and ocular routes [31,34].

In the current study, we developed CS/F NPs and evaluated their potential to be carriers for antibiotics delivery. The prepared CS/F NPs were characterized physicochemically using Fourier transfer infrared spectroscopy (FT-IR), transmission electron microscopy (TEM), and dynamic light scattering (DLS). In vitro antioxidant and anti-inflammatory activities of CS/F NPs in lipopolysaccharide 
(LPS)-stimulated macrophages were evaluated by measuring DPPH scavenging abilities, the level of reactive oxygen species (ROS), superoxide anions $\left(\mathrm{O}_{2}{ }^{-}\right)$and inflammatory mediators such as NO and IL-6. The effect of CS/F NPs on macrophages was visualized using inverted fluorescence microscopic imaging and a flow cytometry system. Moreover, the release profile of antibiotics from NP was quantified using spectrophotometric method with gentamicin (GM) as a model drug.

\section{Results and Discussion}

\subsection{Characterization of CS/F NPS}

Figure 1 shows the FT-IR spectra of CS, fucoidan and CS/F NPs. The CS exhibited characteristic peaks of $\mathrm{NH}_{3}{ }^{+}$(protonated amino group) bending vibrations and $\mathrm{C}=\mathrm{O}$ (carbonyl group) stretching of the secondary amide at $1560 \mathrm{~cm}^{-1}$ and $1650 \mathrm{~cm}^{-1}$, respectively. The peaks at $1150 \mathrm{~cm}^{-1}$ and $1026 \mathrm{~cm}^{-1}$ indicated asymmetric C-O-C stretching and C-O skeletal vibration of CS [19]. The characteristic peaks of the fucoidan spectrum at $1160-1260 \mathrm{~cm}^{-1}$ and $845 \mathrm{~cm}^{-1}$ were associated with the $\mathrm{S}=\mathrm{O}$ asymmetric stretching and C-O-S stretching of the sulfate groups [20]. In the CS/F NPs spectrum, both the characteristic peaks of CS and fucoidan were present, but a red shift of the $\mathrm{C}=\mathrm{O}$ group of CS appeared, indicating possible changes in the environment of the group (Table 1) [35]. The distinctive peaks of the fucoidan spectrum were present at the same wavenumber, revealing that noncovalent interactions occurred between CS and fucoidan. The CS/F NPs were formed through an electrostatic interaction because of a positively charged amino group on the CS and a negatively charged sulfate group on the fucoidan under physiological conditions [19,36].

Table 2 presents the composition of each group of CS/F NPs. The characteristics of CS/F NPs in phosphate-buffered saline were shown in Table 3. The C3F1, C4F1, and C5F1 NPs exhibited comparable particle sizes as the $\mathrm{pH}$ values increased from 6.0 to 7.4. These results indicated that $\mathrm{C} 3 \mathrm{~F} 1, \mathrm{C} 4 \mathrm{~F} 1$, and $\mathrm{C} 5 \mathrm{~F} 1 \mathrm{NPs}$ remained stable and were insensitive to environmental $\mathrm{pH}$ changes. By contrast, the $\mathrm{C} 1 \mathrm{~F} 1$ and $\mathrm{C} 2 \mathrm{~F} 1 \mathrm{NPs}$ exhibited significant $\mathrm{pH}$ sensitive properties. The C1F1 NPs swelled considerably as the $\mathrm{pH}$ level rose, and discomposed at $\mathrm{pH}$ 7.4. The $\mathrm{C} 2 \mathrm{~F} 1 \mathrm{NPs}$ demonstrated the same trend as the $\mathrm{C} 1 \mathrm{~F} 1$ NPs, but swelled at a higher $\mathrm{pH}$ value ( $\mathrm{pH}$ 7.2). The results can be explained based on the charge ratio of CS to fucoidan for each group (Table 2). The charge ratios of CS to fucoidan for the C5F1, C4F1, and $\mathrm{C} 3 \mathrm{~F} 1 \mathrm{NPs}$ are 5.26:1, 4.21:1, and 3.16:1, respectively. Although the $\mathrm{pH}$ value rose to 7.4, which was higher than the $6.5 \mathrm{pKa}$ of $\mathrm{CS}$, the excessive ammonium ions could still form stable electronic interactions with the sulfate groups [36]. In the C1F1 NPs, the CS and fucoidan exhibited comparable amounts of charges. As the $\mathrm{pH}$ value was higher than 6.5, the deionized ammonium ions caused the NPs to swell and disintegrate rapidly. In the C2F1 NPs, the positive CS charges were slightly higher than the negative fucoidan charges. As the $\mathrm{pH}$ value increased, the amount of positive charges was insufficient to form stable nanoparticles. Therefore, the C2F1 NPs were less sensitive to $\mathrm{pH}$ changes than the C1F1 NPs. 
Figure 1. The FTIR spectra of CS, F, and CS/F NPs.

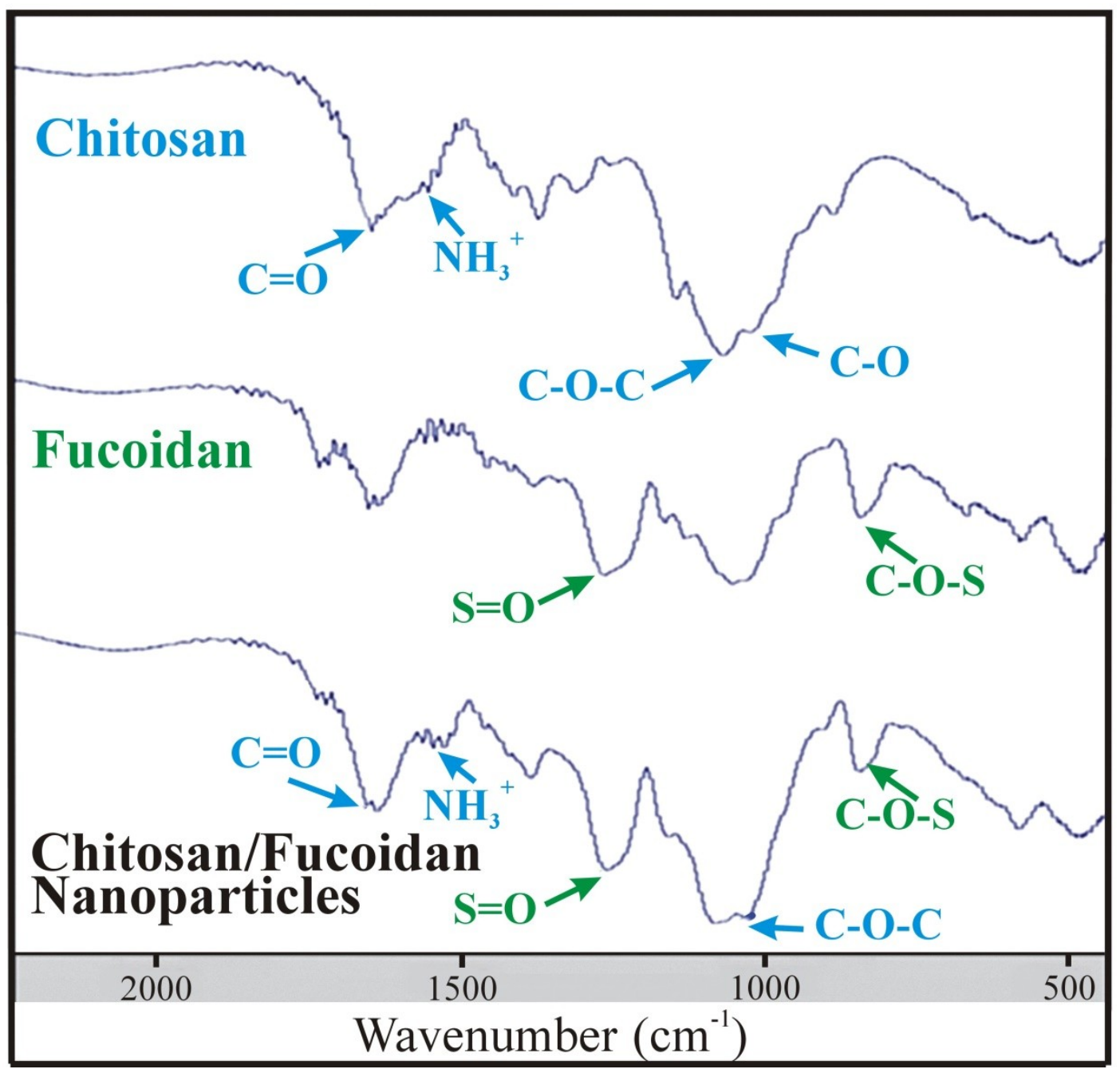

Table 1. Characteristic peaks of FTIR spectrum.

\begin{tabular}{cl}
\hline Compound & \multicolumn{1}{c}{ Characteristic Peaks } \\
\hline Chitosan (CS) & $-\mathrm{NH}_{3}^{+}\left(1560 \mathrm{~cm}^{-1}\right) ;-\mathrm{C}=\mathrm{O}\left(1650 \mathrm{~cm}^{-1}\right) ; \mathrm{C}-\mathrm{O}-\mathrm{C}\left(1150 \mathrm{~cm}^{-1}\right) ; \mathrm{C}-\mathrm{O}\left(1026 \mathrm{~cm}^{-1}\right)$ \\
\hline Fucoidan (F) & $\mathrm{S}=\mathrm{O}\left(1160-1260 \mathrm{~cm}^{-1}\right) ; \mathrm{C}-\mathrm{O}-\mathrm{S}\left(845 \mathrm{~cm}^{-1}\right)$ \\
\hline CS/F NPs & $\begin{array}{l}\text { Both the characteristic peaks of CS and fucoidan were present, but a red } \\
\text { shift of the } \mathrm{C}=\mathrm{O} \text { group of CS appeared. }\end{array}$ \\
\hline
\end{tabular}

Table 2. The composition of the prepared CS/F NPs. The CS and fucoidan used was $200 \mu \mathrm{L}$ for each sample. The final $\mathrm{pH}$ value of the CS/F NPs solutions is 6.0.

\begin{tabular}{ccccc}
\hline Group & $\begin{array}{c}\text { Chitosan } \\
(\mathbf{m g} / \mathbf{m L} \mathbf{p H} \mathbf{~ 6 . 0})\end{array}$ & $\begin{array}{c}\text { Fucoidan } \\
(\mathbf{m g} / \mathbf{m L}, \mathbf{p H ~ 6 . 0 )}\end{array}$ & $\begin{array}{c}\text { Weight Ratio } \\
(\mathbf{C S}: \mathbf{F})\end{array}$ & $\begin{array}{c}\text { Charge Ratio } \\
\text { (CS:F) }\end{array}$ \\
\hline C1F1 & 5 & 5 & $1: 1$ & $1.05: 1$ \\
C2F1 & 10 & 5 & $2: 1$ & $2.11: 1$ \\
C3F1 & 15 & 5 & $3: 1$ & $3.16: 1$ \\
C4F1 & 20 & 5 & $4: 1$ & $4.21: 1$ \\
C5F1 & 25 & 5 & $5: 1$ & $5.26: 1$ \\
\hline
\end{tabular}


Table 3. The characteristics of CS/F NPs under phosphate-buffered saline, including particle size, zeta potential and PDI value.

\begin{tabular}{|c|c|c|c|c|c|}
\hline & \multicolumn{5}{|c|}{ Particles Size (nm) } \\
\hline & C1F1 & C2F1 & C3F1 & C4F1 & C5F1 \\
\hline $\mathrm{pH} 6.0$ & $372 \pm 38$ & $340 \pm 5$ & $331 \pm 6$ & $344 \pm 2$ & $326 \pm 21$ \\
\hline pH 6.6 & $865 \pm 129$ & $331 \pm 6$ & $312 \pm 2$ & $327 \pm 5$ & $316 \pm 3$ \\
\hline pH 7.0 & $1050 \pm 149$ & $334 \pm 11$ & $298 \pm 8$ & $330 \pm 4$ & $293 \pm 10$ \\
\hline pH 7.2 & $1051 \pm 124$ & $429 \pm 25$ & $309 \pm 4$ & $324 \pm 4$ & $274 \pm 6$ \\
\hline \multirow[t]{3}{*}{$\mathrm{pH} 7.4$} & $1252 \pm 114$ & $747 \pm 52$ & $497 \pm 54$ & $348 \pm 4$ & $271 \pm 6$ \\
\hline & \multicolumn{5}{|c|}{ Zeta potential $(\mathrm{mV})$} \\
\hline & C1F1 & $\mathrm{C} 2 \mathrm{~F} 1$ & $\mathrm{C} 3 \mathrm{~F} 1$ & C4F1 & $\mathrm{C} 5 \mathrm{~F} 1$ \\
\hline pH 6.0 & $8.0 \pm 0.2$ & $11.7 \pm 0.8$ & $13.8 \pm 0.3$ & $14.5 \pm 0.6$ & $13.2 \pm 0.9$ \\
\hline pH 6.6 & $0.9 \pm 2.8$ & $7.8 \pm 0.5$ & $9.0 \pm 0.7$ & $10.4 \pm 1.6$ & $9.6 \pm 0.4$ \\
\hline $\mathrm{pH} 7.0$ & $-3.1 \pm 2.7$ & $4.1 \pm 0.5$ & $5.4 \pm 0.8$ & $6.1 \pm 0.6$ & $5.9 \pm 0.5$ \\
\hline pH 7.2 & $-3.7 \pm 1.5$ & $3.3 \pm 0.6$ & $3.4 \pm 0.1$ & $3.9 \pm 0.6$ & $4.4 \pm 0.7$ \\
\hline \multirow[t]{3}{*}{$\mathrm{pH} 7.4$} & $-4.7 \pm 1.3$ & $0.7 \pm 0.6$ & $-1.1 \pm 1.4$ & $3.6 \pm 3.1$ & $1.8 \pm 0.5$ \\
\hline & \multicolumn{5}{|c|}{ PDIs } \\
\hline & $\mathrm{C} 1 \mathrm{~F} 1$ & $\mathrm{C} 2 \mathrm{~F} 1$ & $\mathrm{C} 3 \mathrm{~F} 1$ & $\mathrm{C} 4 \mathrm{~F} 1$ & $\mathrm{C} 5 \mathrm{~F} 1$ \\
\hline pH 6.0 & $0.24 \pm 0.02$ & $0.28 \pm 0.01$ & $0.31 \pm 0.01$ & $0.25 \pm 0.02$ & $0.35 \pm 0.03$ \\
\hline pH 6.6 & $0.29 \pm 0.04$ & $0.29 \pm 0.01$ & $0.27 \pm 0.03$ & $0.25 \pm 0.01$ & $0.37 \pm 0.02$ \\
\hline pH 7.0 & $0.37 \pm 0.07$ & $0.29 \pm 0.03$ & $0.27 \pm 0.02$ & $0.26 \pm 0.01$ & $0.32 \pm 0.03$ \\
\hline $\mathrm{pH} 7.2$ & $0.33 \pm 0.04$ & $0.38 \pm 0.03$ & $0.30 \pm 0.04$ & $0.26 \pm 0.01$ & $0.29 \pm 0.02$ \\
\hline pH 7.4 & $0.41 \pm 0.04$ & $0.28 \pm 0.03$ & $0.28 \pm 0.01$ & $0.26 \pm 0.02$ & $0.24 \pm 0.01$ \\
\hline
\end{tabular}

Data are mean $\pm \mathrm{SD}$ of values calculated on 3 distinct batches $(n=3)$.

The zeta potential tended to decrease as the $\mathrm{pH}$ changed from 6.0 to 7.4 in all groups (Table 3). The results were due to the number of positive ammonium ion decreasing as the $\mathrm{pH}$ increased. However, the C4F1 and C5F1 NPs still maintained a positive zeta potential at $\mathrm{pH}$ 7.4. The excessive amount of CS caused these results. Considering that NPs interact with cell populations along the respiratory tract containing negatively charged cell membranes, including mucus, epithelial cells, and macrophages, positively charged NPs are favorable [37]. The particle sizes of C3F1, C4F1, and C5F1 NPs were approximately $300 \mathrm{~nm}, 330 \mathrm{~nm}$, and $270 \mathrm{~nm}$, respectively, at pH 6.0 to $\mathrm{pH} 7.4$ (Table 3). Nanosized particles have been reported to have an obstinate residency in the lungs [38] and an ability to evade phagocytosis and mucociliary clearance [39,40]. Moreover, nanoparticles exhibiting an approximate diameter of $250 \mathrm{~nm}$ are likely able to diffuse through lung mucus more easily than larger NP formulations can [41]. Brownian diffusion is the potential mechanism for the deposition of particles exhibiting a diameter of less than $500 \mathrm{~nm}$ and occurring in the acinar region of the lungs [42]. Figure 2A presents the storage stability of the C3F1, C4F1, and C5F1 NPs. The particle size variation of the C5F1 NPs was the least among all of the groups. The C5F1 NPs could maintain compactness and stability for 25 day. The C5F1 NPs in TEM images were spherical and exhibited diameters of approximately 230-250 nm (Figure 2B). 
Figure 2. (A) Storage stability of C3F1, C4F1 and C5F1 NPs at $4{ }^{\circ} \mathrm{C}$; (B) TEM image of C5F1 NPs in phosphate-buffered saline (pH 7.4).
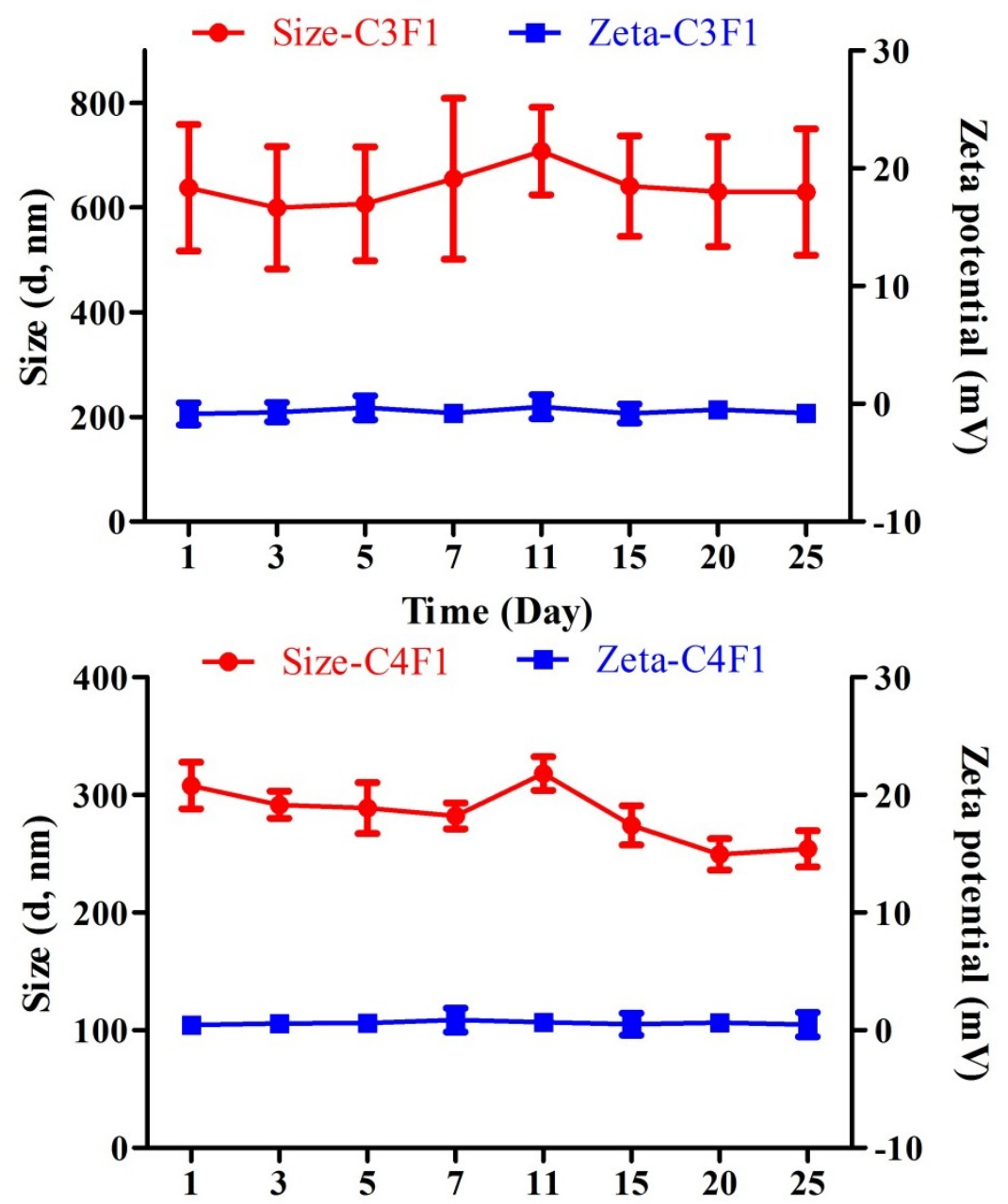

Time (Day)

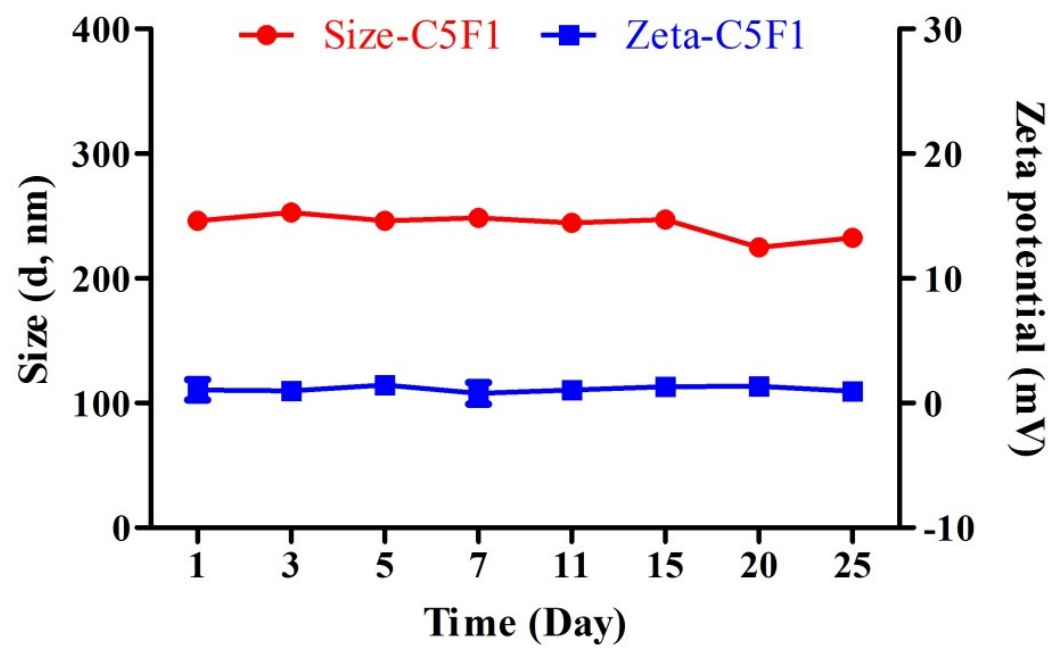

(A) 
Figure 2. Cont.

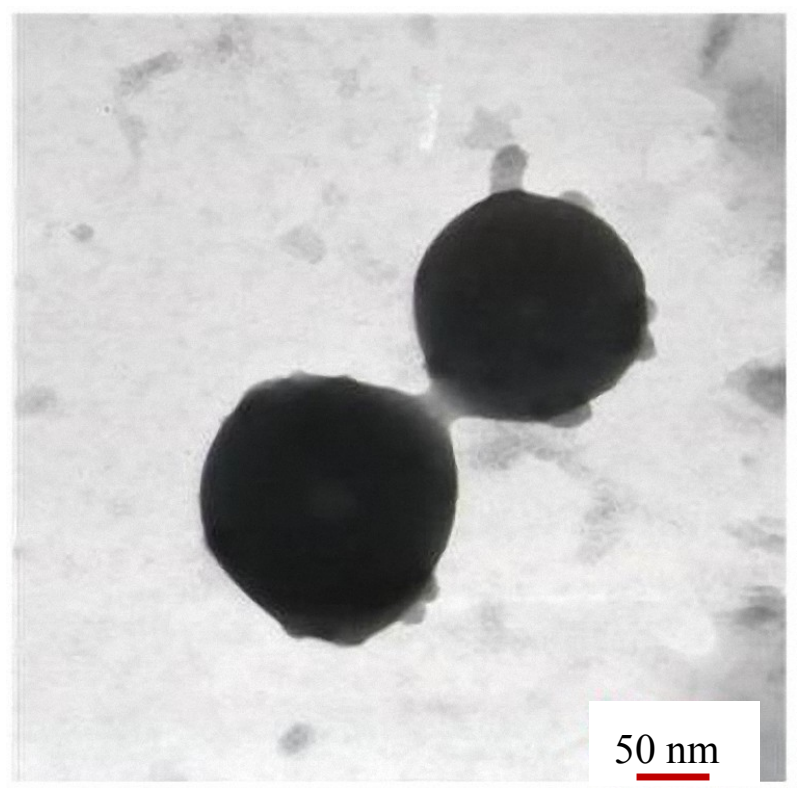

(B)

Figure 3. DPPH radical scavenging activity of (A) C3F1, C4F1, and C5F1 NPs and (B) CS, and F. Using vitamin C as positive control. Data are mean $\pm \mathrm{SD}$ of values calculated on 3 distinct batches $(n=3)$.

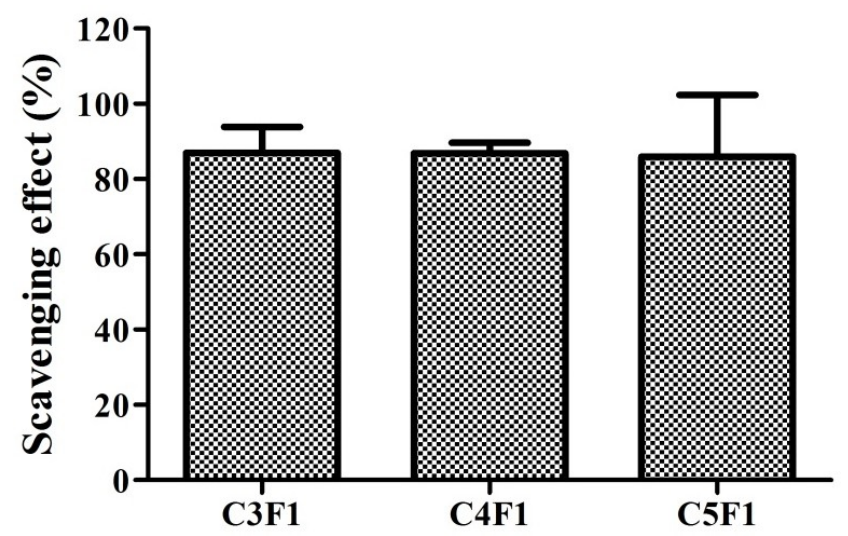

(A)

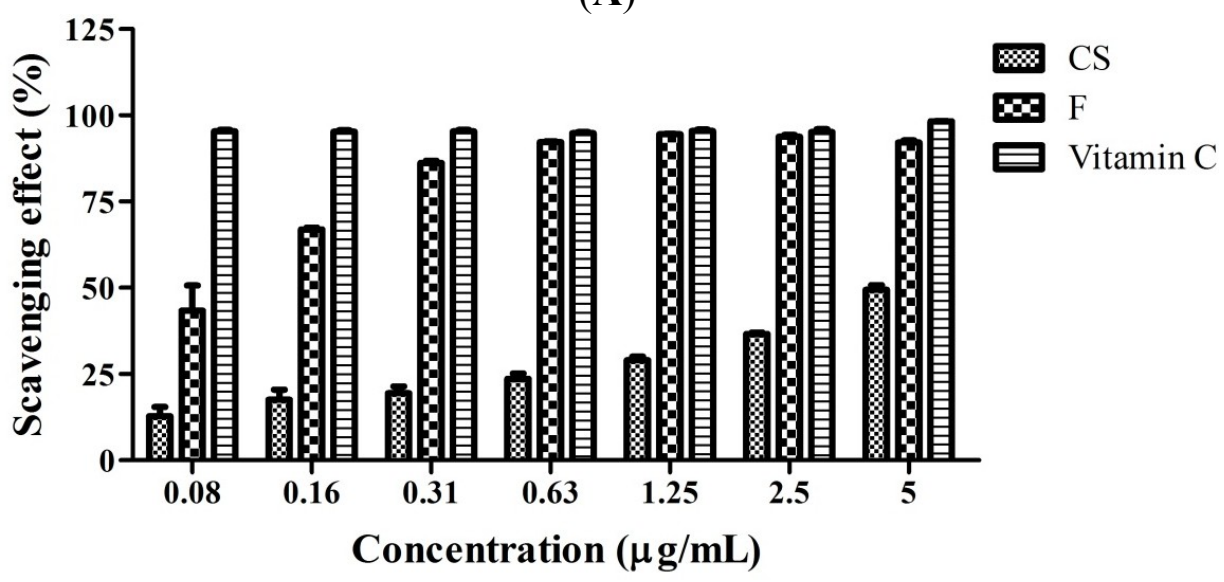

(B) 


\subsection{DPPH Scavenging Activity of $C S / F N P S$}

As shown in Figure 3A, the C3F1, C4F1, and C5F1 NPs demonstrated a DPPH scavenging activity of up to $80 \%$. No significant difference among these NPs was observed. Furthermore, Figure 3B illustrates the concentration effect of CS and fucoidan on scavenging percentages to evaluate whether CS or fucoidan is responsible for DPPH scavenging activity. Using vitamin $\mathrm{C}$ as a positive control group, the DPPH scavenging effect was approximately $90 \%$ when the fucoidan concentration was higher than $0.31 \mathrm{mg} / \mathrm{mL}$ (Figure 3B). In addition, fucoidan presented a significantly higher scavenging effect than CS did. These results suggested that the DPPH scavenging effect of CS/F NPs primarily derives from fucoidan.

Figure 4. (A) ROS generation after exposure CS/F NPs to RAW 264.7 cells for $24 \mathrm{~h}$. The intracellular ROS is observed by fluorescence microscope with green spots; (B) Effect of NPs on ROS production of RAW 264.7 and (C) LPS-induced RAW 264.7 cells detected by flow cytometry. Data are mean \pm SD of values calculated on 5 distinct batches $(n=5)$. Statistical analysis was performed by one-way ANOVA. ** $p<0.01$ versus control. $* * * p<0.001$ versus control. ${ }^{\# \#} p<0.001$ versus LPS.
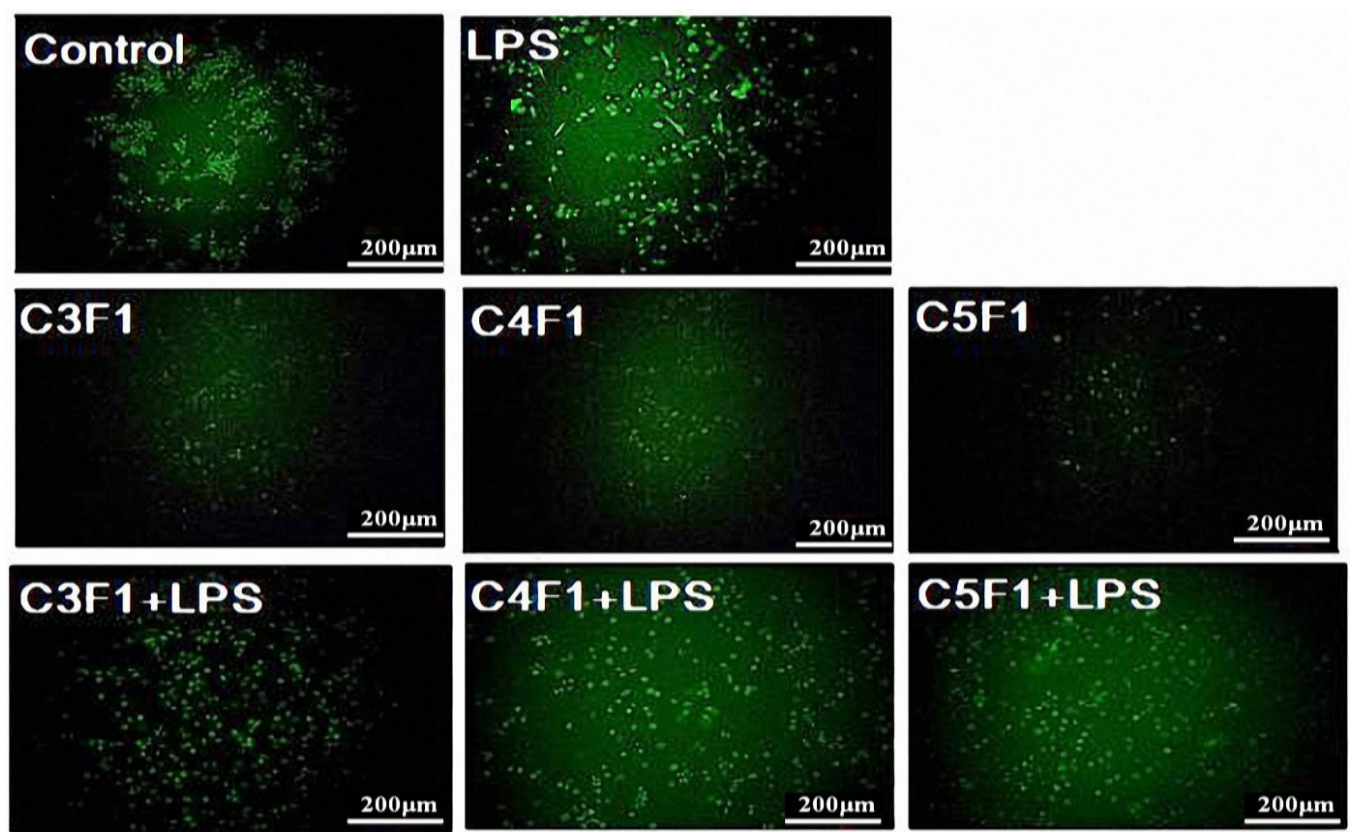

(A)

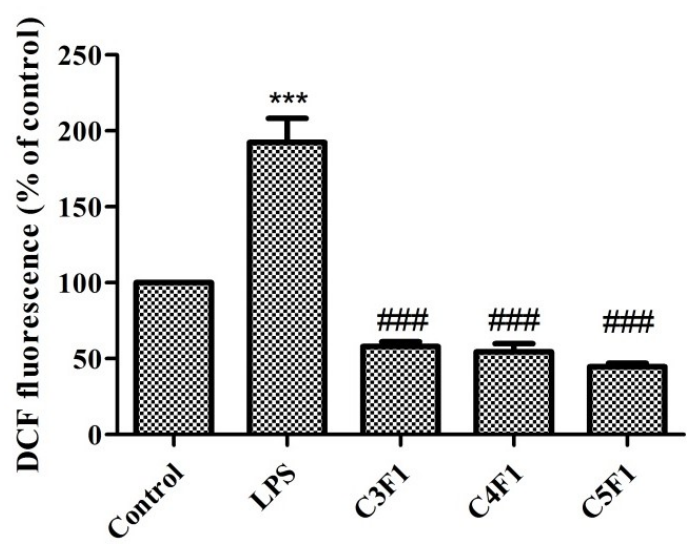

(B)

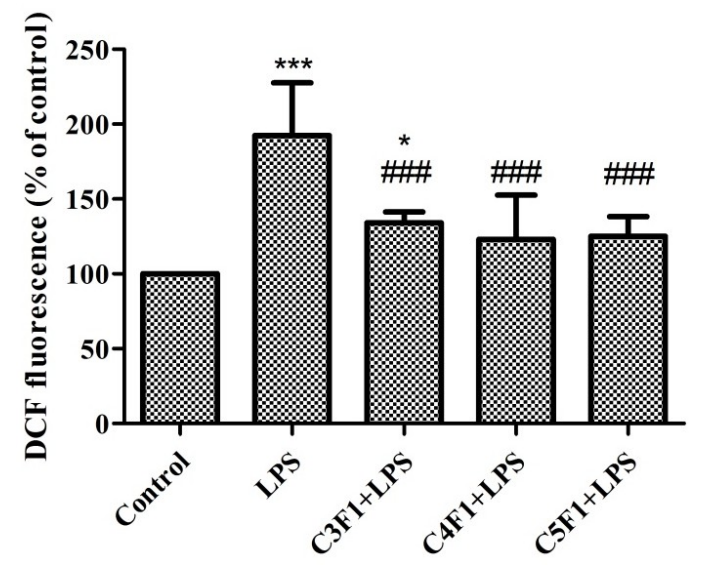

(C) 


\subsection{Effects of CS/F NPs on ROS Production}

Regarding the antioxidant activity test, the lipopolysaccharide (LPS)-induced intracellular ROS production against the RAW 264.7 cells was studied. The increased ROS after adding LPS was easily visualized using fluorescence microscopy, as shown in Figure 4A. Regarding quantification, the level of generated ROS was then determined using a flow cytometric analysis (Figure 4B,C). The ROS level increased in the LPS-induction group and was comparable with that of the control group in the C3F1, C4F1, and C5F1 groups (Figure 4B). Furthermore, C3F1, C4F1, and C5F1 NPs all significantly reduced the level of ROS induced by the LPS (Figure 4C). These results suggest that the CS/F NPs effectively reacted with ROS resulting in a reduced concentration.

We also used the nitroblue tetrazolium (NBT) assay to monitor superoxide anion $\left(\mathrm{O}_{2}{ }^{-}\right)$, which is an ROS frequently observed in various phagocytic cells. As shown in Figure 5A, the C3F1, C4F1, and $\mathrm{C} 5 \mathrm{~F} 1$ groups exerted no effect on $\mathrm{O}_{2}{ }^{-}$production, but the LPS induced a significant $\mathrm{O}_{2}{ }^{-}$level increase. Figure 5B shows that the $\mathrm{O}_{2}{ }^{-}$level induced by the LPS decreased considerably after CS/F NPs were added. The effect was observed in the C3F1, C4F1, and C5F1 groups. According to the experimental results, the CS/F NPs exhibited an effective inhibitory effect on $\mathrm{O}_{2}^{-}$concentration.

Chitosan was reported to demonstrate antioxidant activities because of a strong hydrogen-donating ability [43]. Fucoidan obtained from Fucus vesiculosus exhibited excellent scavenging capacities on the hydroxyl and superoxide radicals $[25,44]$. The antioxidant ability of CS/F NPs revealed in our experiments was reasonable and corresponded with that of the aforementioned previous study. The CS/F NPs developed in the current study could be potential antioxidant carriers in a delivery system. Both chitosan and fucoidan play vital roles in the antioxidant property of CS/F NPs.

Figure 5. Effect of C3F1, C4F1, and C5F1 NPs on $\mathrm{O}_{2}^{-}$production of (A) RAW 264.7 cells and (B) LPS-induced RAW 264.7 cells. Data are mean \pm SD of values calculated on 3 distinct batches $(n=3)$. Statistical analysis was performed by one-way ANOVA. ** $p<0.01$ versus control, $* * * p<0.001$ versus control. ${ }^{\#} p<0.05$ versus LPS, ${ }^{\#} p<0.01$ versus LPS, \#\#\# $p<0.001$ versus LPS.

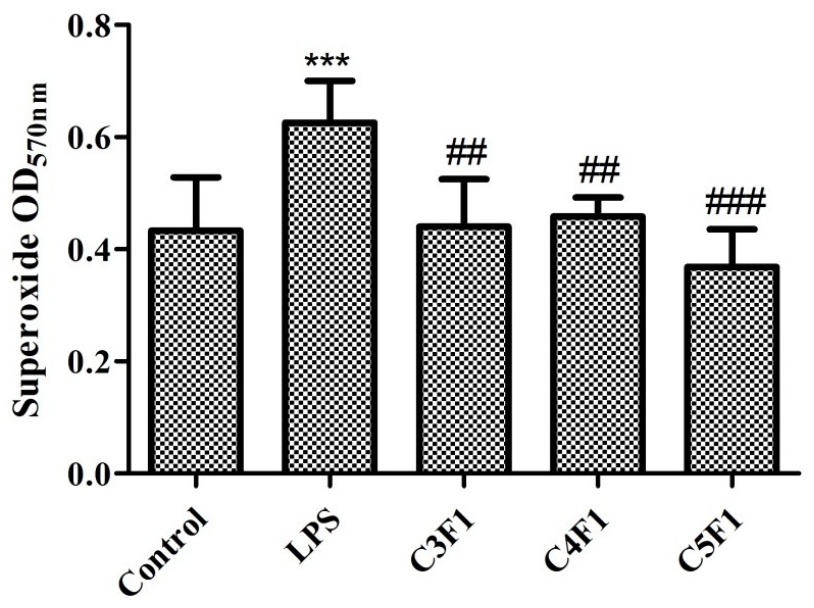

(A) 
Figure 5. Cont.

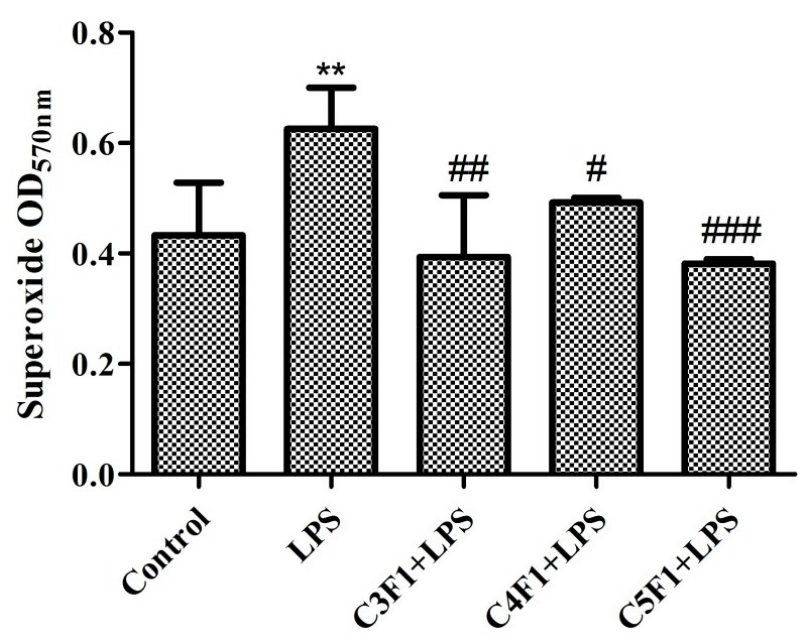

(B)

\subsection{Anti-Inflammatory Effect of CS/F NPS}

LPS, a highly conserved cell wall component of gram-negative bacteria, is known to initiate signaling cascade for inflammatory mediator expression including cytokines, such as IL-6, and cytotoxic molecules, such as NO. Thus, NO and IL-6 are primary molecules involved in macrophage-mediated innate immune responses [45]. In the current study, LPS treatment caused a significant increase in NO and IL-6 production in RAW 264.7 cells (Figure 6). In the C3F1, C4F1, and C5F1 groups, the amount of NO and IL-6 was comparable with that of the control group (Figure 6A). As shown in Figure 6B, LPS-induced NO and IL-6 production caused no variation between the LPS and LPS + NP groups (including the LPS $+\mathrm{C} 3 \mathrm{~F} 1$, LPS $+\mathrm{C} 4 \mathrm{~F} 1$, and LPS $+\mathrm{C} 5 \mathrm{~F} 1$ groups). Based on the experimental results, the CS/F NPs activated no host immune cells into inflammation-mediated cytotoxic conditions induced by IL-6 production and NO generation.

Figure 6. Effect of C3F1, C4F1, and C5F1 NPs on NO (left panel) and IL-6 (right panel) production of (A) RAW 264.7 cells and (B) LPS-induced RAW 264.7 cells. Data are mean $\pm \mathrm{SD}$ of values calculated on 3 distinct batches $(n=3)$. Statistical analysis was performed by one-way ANOVA. *** $p<0.001$ versus control. ${ }^{\# \# \#} p<0.001$ versus LPS.
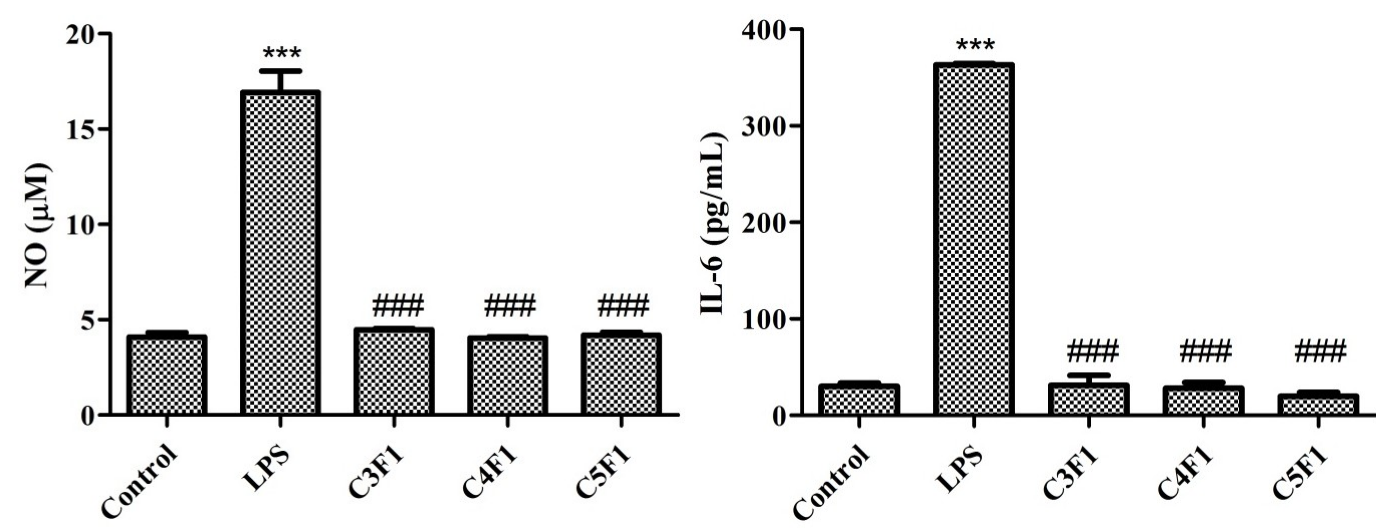

(A) 
Figure 6. Cont.
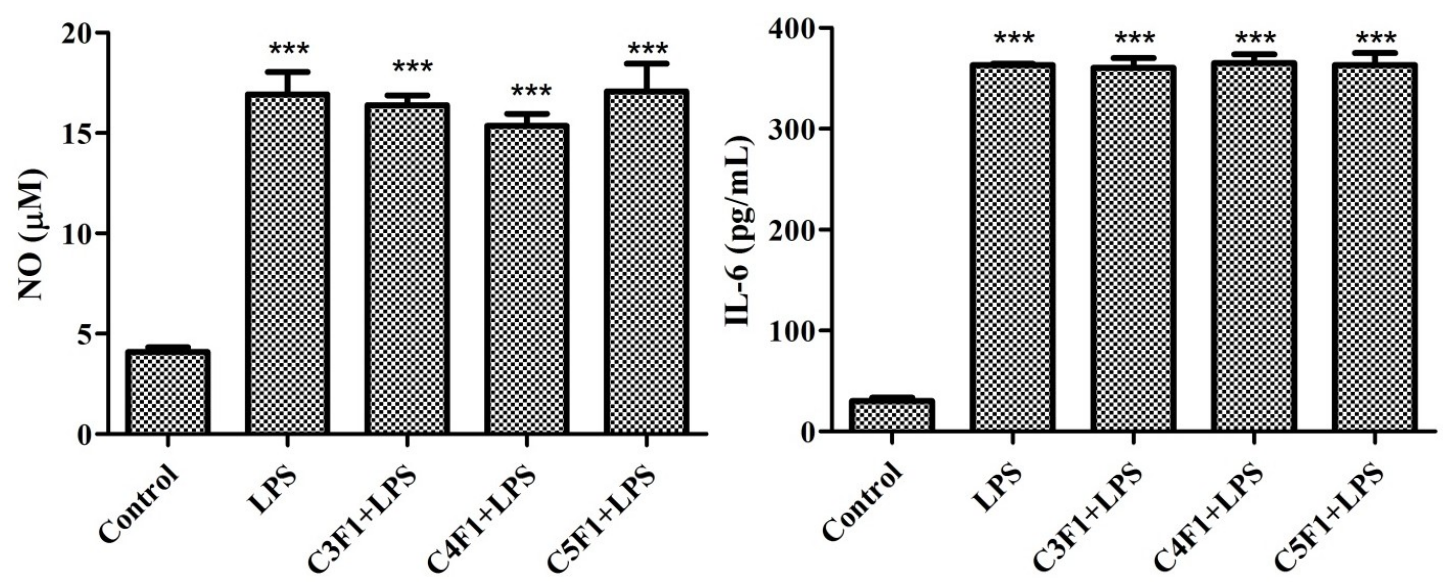

(B)

\subsection{Cytotoxicity of $C S / F N P S$}

This study also attempted to confirm the extent to which CS/F NPs affect cell viability by adding the CS/F NPs to an A549 cell culture. Figure 7A presents the cytotoxic effects of the CS/F NPs on the A549 cells by using MTT assay analyses. The cell viability was comparable in the C3F1, C4F1, and C5F1 NPs, which were 102.5\%, 105.5\%, and 105.6\%, respectively. Furthermore, we also plotted the cell viability versus the concentration of the NPs (Figure 7B). The results indicated that cell viability was higher than $80 \%$ in the C5F1 NPs as its concentration was between $0.375 \mathrm{mg} / \mathrm{mL}$ and $3 \mathrm{mg} / \mathrm{mL}$. The cytotoxicity effects of the C5F1 NPs on the A549 cells were exerted in a dose-independent manner.

Figure 7. (A) Effect of C3F1, C4F1, and C5F1 NPs on A549 cell viability measured by MTT assays $24 \mathrm{~h}$ post-coculturing; (B) Effect of C5F1 NPs concentration on A549 cell viability measured by MTT assay $24 \mathrm{~h}$ post-coculturing. Data are mean $\pm \mathrm{SD}$ of values calculated on 5 distinct batches $(n=5)$. Statistical analysis was performed by one-way ANOVA. Data with different letters express significant difference at $p<0.05$.

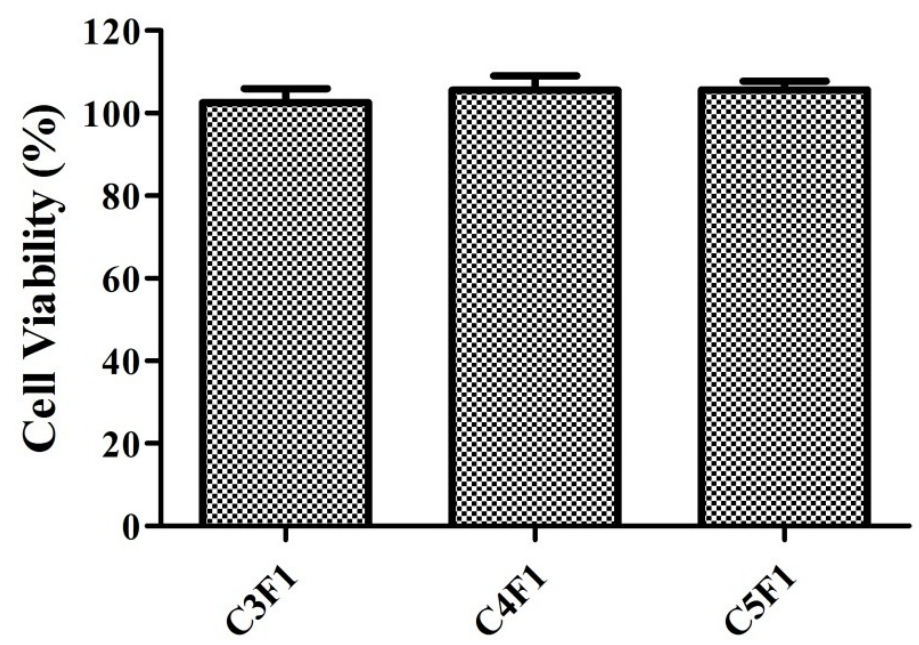

(A) 
Figure 7. Cont.

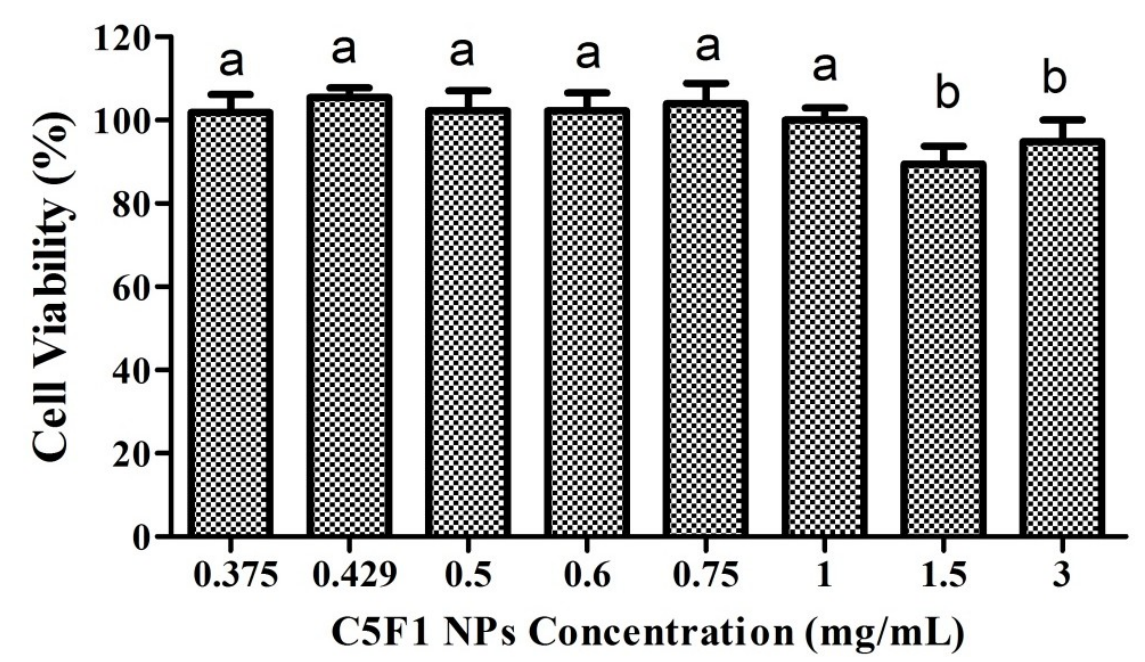

(B)

\subsection{In Vitro Release of Gentamicin (GM)}

In this study, GM is used as a model antibiotic for in vitro releasing test. The encapsulation efficiency of GM in CS/F NPs was 94\%. Figure 8 plots the amount of GM released from the prepared NPs. The release of GM exhibited a biphasic profile. After an initial $10 \mathrm{~h}$ burst release of GM, the rate of release slowed, as reflected by the decreasing slope of the plot of cumulative amount of GM released against time. For the first $10 \mathrm{~h}$, the linear curve exhibited a zero-order delivery of GM. After $72 \mathrm{~h}$ releasing, the cumulative percentage of GM released was about $99 \%, 98 \%$ and $99 \%$ in $\mathrm{C} 3 \mathrm{~F} 1$, C4F1 and C5F1 groups, respectively. The rapid releasing profile can be explained by reference to the hydrophilic property of GM. The dissolved GM could diffuse into the release medium easily. Moreover, GM on the surface of NPs might contribute to speedy releasing. The slow releasing curve in the second phase is due to polymer degradation [46]. GM is an aminoglycoside antibiotic widely used for treating many types of bacterial infections in airway inflammatory diseases, particularly those caused by Gram-negative bacteria. The biphasic releasing of GM is effective for bacterial growth inhibition. In the initial stage, rapid release of GM could inhibit bacterial growth efficiently; in the second stage, sustained releasing of GM could suppress bacterial infection continuously. Briefly, CS/F NPs prepared in this study are potential carriers for antibiotics delivery.

Fucoidan mimics certain biological activities of heparin, including anticoagulant and growth factor binding properties $[47,48]$. Heparin and fucoidan have been reported to bind and dimerize stromal cell-derived factor-1(SDF-1) [49] and to enhance the basic fibroblast growth factor (bFGF) induced tube formation of endothelial cells [50]. Numerous studies have focused on heparin in pharmacology and biomaterial science; however, the feasibility of using fucoidan in biomaterials and delivery systems remains limited. Fucoidan derived from brown algae is highly promising for use in clinical settings as an alternative to heparin obtained from animals, and thus further studies on this aspect of fucoidan use are warranted. 
Figure 8. The release kinetics of GM from CS/F NPs.

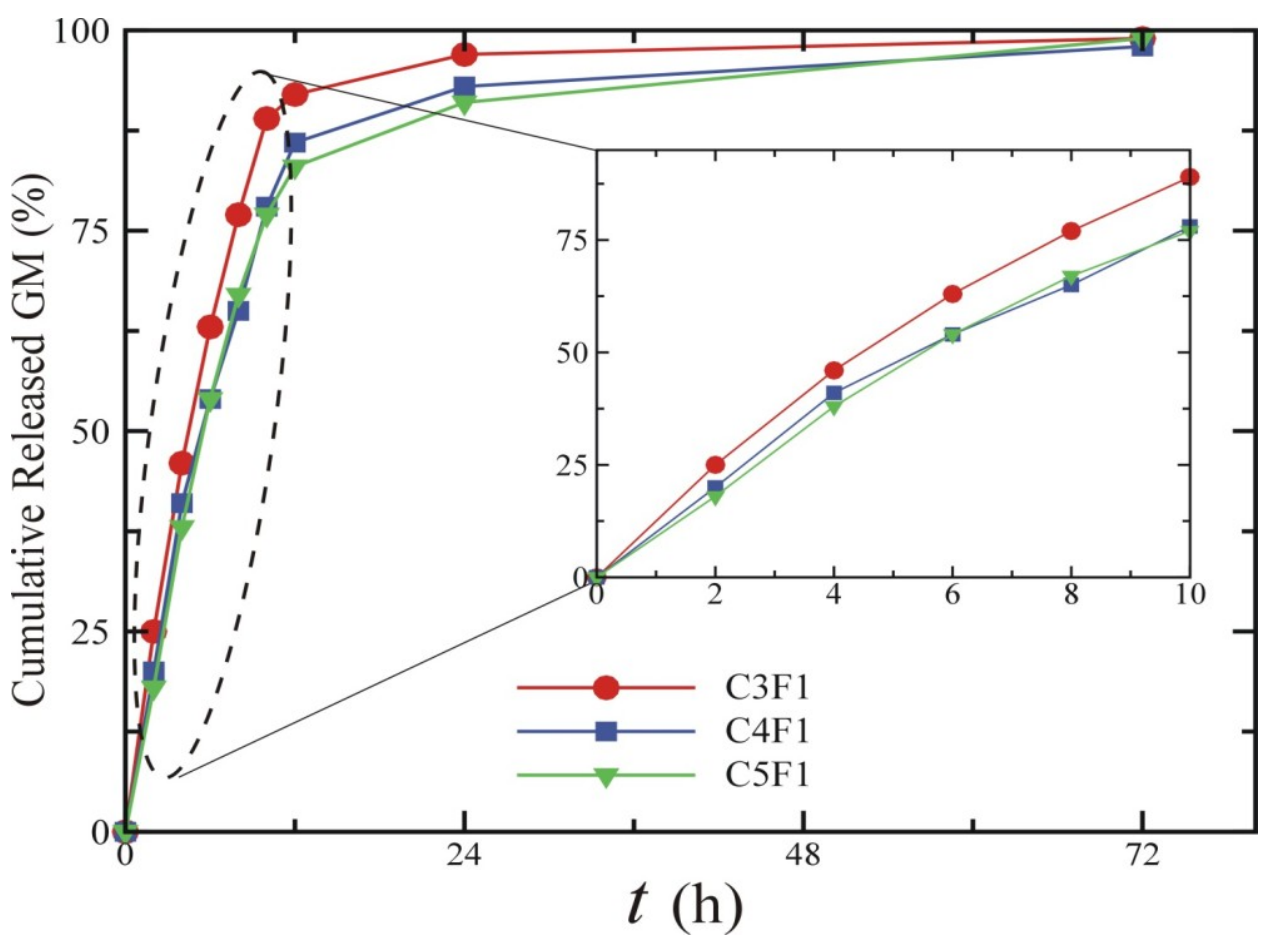

\section{Experimental Section}

Chitosan (deacetylation degree $\geq 75 \%$ ) and fucoidan (from $F$. vesiculosus) were supplied by Sigma Chemical Co. (St. Louis, MO, USA). Human A549 lung cells (BCRC 60074) and Murine RAW 264.7 macrophages (BCRC 60001) were both obtained from the Bioresource Collection and Research Center, Hsinchu, Taiwan. All of the other chemicals were of reagent grade and were purchased from Sigma Chemical Co. unless stated otherwise.

\subsection{Preparation of $C S / F N P S$}

A simple polyelectrolyte self-assembly method was used in this study to prepare the CS/F NPs by performing ultrasonication at room temperature. To increase solubility, the CS was treated with $\mathrm{H}_{2} \mathrm{O}_{2}$ to produce low-molecular-weight CS (38 kDa) by using our previously developed method [20]. The NPs with various CS-to-fucoidan weight ratios, including 1:1, 2:1, 3:1, 4:1, and 5:1 (named the C1F1, $\mathrm{C} 2 \mathrm{~F} 1, \mathrm{C} 3 \mathrm{~F} 1, \mathrm{C} 4 \mathrm{~F} 1$ and $\mathrm{C} 5 \mathrm{~F} 1$ groups, respectively), were prepared by adding a $200 \mu \mathrm{L}$ CS/acetic acid solution ( $\mathrm{pH}$ 6.0) at varying concentrations $(5 \mathrm{mg} / \mathrm{mL}, 10 \mathrm{mg} / \mathrm{mL}, 15 \mathrm{mg} / \mathrm{mL}, 20 \mathrm{mg} / \mathrm{mL}$, and $25 \mathrm{mg} / \mathrm{mL}$ ) using a pipette into a $200 \mu \mathrm{L}$ aqueous fucoidan solution $(5 \mathrm{mg} / \mathrm{mL}, \mathrm{pH} 6.0)$ under probe-type ultrasonicating (pulse-on $3 \mathrm{~s}$ and pulse-off $7 \mathrm{~s}$; total $30 \mathrm{~s}$ ) at ice bath. The self-assembled nanoparticles were collected using centrifugation at $14,000 \mathrm{rpm}$ for $5 \mathrm{~min}$. The final $\mathrm{pH}$ value of the CS/F NPs solutions is 6.0. The supernatants were removed, and the NPs were lyophilized or resuspended in phosphate buffered saline for further study. 


\subsection{Characterization of $C S / F N P S$}

FT-IR (Brucker Tensor 27) was used to analyze the peak variation of amino and sulfate groups on the prepared NPs. A Zetasizer nano ZS (Malvern Instruments Ltd., Worcestershire, UK) was used to measure the size distribution, zeta potential, and polydispersity index (PDI) of CS/F NPs. We used TEM (JEOL, Tokyo, Japan) for observing morphology. To prepare the TEM sample, a drop of the NP suspension was applied to a 200-mesh copper grid for approximately $10 \mathrm{~min}$. A filter paper was then taped onto the grid to remove surface water, and the NP was fixed in $1 \%$ formaldehyde for $2-3 \mathrm{~h}$. The sample was then positively stained using an alkaline bismuth solution [19,51].

\subsection{Cell Culture}

For the A549 cells, the culture medium used was an F-12K medium (Gibco, Grand Island, NY, USA) supplemented with $10 \% \mathrm{FBS}, 1.5 \mathrm{~g} / \mathrm{L}$ sodium bicarbonate, 100 units $/ \mathrm{mL}$ penicillin, and $100 \mu \mathrm{g} / \mathrm{mL}$ streptomycin. For the RAW 264.7 cells, the culture medium was Dulbecco's modified Eagle's medium (DMEM) (Gibco, Grand Island, NY, USA) supplemented with 10\% FBS, 2.5 g sodium bicarbonate, $3.7 \mathrm{~g}$ HEPES, 100 units $/ \mathrm{mL}$ penicillin, and $100 \mu \mathrm{g} / \mathrm{mL}$ streptomycin. The cultures were maintained at $37{ }^{\circ} \mathrm{C}$ in a humidified atmosphere containing $5 \%$ carbon dioxide.

\subsection{DPPH Scavenging Test}

Chitosan and fucoidan were diluted in $\mathrm{ddH}_{2} \mathrm{O}$ for each experimental concentration $(0-5 \mathrm{mg} / \mathrm{mL})$. Subsequently, $50 \mu \mathrm{L}$ of $0.2 \mathrm{mM}$ 1,1-diphenyl-2-picrylhydrazyl (DPPH) solution was added to a $50 \mu \mathrm{L}$ CS or fucoidan solution and incubated at room temperature for $45 \mathrm{~min}$ in the dark. The absorbance was measured using a SpectraMax 340 $\mathrm{PC}^{384}$ microplate spectrophotometer (Molecular Devices, Sunnyvale, CA, USA) at $517 \mathrm{~nm}$. Vitamin C was used as a positive control [52]. Scavenging activity was calculated using the following formula:

$$
\text { Scavenging Effect }(\%)=\left(1-\frac{\text { CS or fucoidan value }}{\text { Control }}\right) \times 100 \%
$$

The results of each concentration were calculated on 3 distinct batches.

\subsection{Reactive Oxygen Species Determination}

The intracellular ROS was determined using 2',7'-dichlorofluorescin diacetate (DCFH-DA) [52] and NBT reduction assay [53]. The DCFH-DA enters the cell where it reacts with ROS to form the highly fluorescent compound dichlorofluorescein (DCF). Briefly, RAW 264.7 cells were planted in 12-well plates at a density of $2.0 \times 10^{5}$ cells/well and allowed to attach for $24 \mathrm{~h}$ before treatment. After the cells were exposed to CS/F NPs and LPS for $24 \mathrm{~h}$, the medium was changed to a serum-free DMEM containing $20 \mu \mathrm{M}$ of DCFH-DA and incubated for $30 \mathrm{~min}$ at $37{ }^{\circ} \mathrm{C}$. The cells were then washed once with PBS, collected using $0.25 \%$ trypsinization, rewashed with PBS, and then resuspended in $1 \mathrm{~mL}$ of PBS. The cells were observed using an inverted fluorescence microscope (Olympus IX71, Tokyo, Japan). The fluorescence was then determined at $488 \mathrm{~nm}$ excitation and $525 \mathrm{~nm}$ emission by using a Cytomics FC500 flow cytometry system (BD Biosciences Aria, Franklin Lakes, NJ, USA). 
Regarding the NBT reduction analysis, RAW 264.7 cells $\left(1.0 \times 10^{6}\right.$ cells/well $)$ were planted in 6-well plates and allowed to attach for $24 \mathrm{~h}$ before treatment. After the cells were exposed to CS/F NPs and LPS for $24 \mathrm{~h}$, the cells were harvested using centrifugation and suspended in $300 \mu \mathrm{L}$ of NBT solution for $1 \mathrm{~h}$. Subsequently, $50 \mu \mathrm{L}$ of $2 \mathrm{~N} \mathrm{HCl}$ was added to terminate the reaction. After centrifugation, $200 \mu \mathrm{L}$ of dimethylsulfoxide was added to the cell pellets to solubilize the formazan deposits. The amount of formazan formed was assayed spectrophotometrically at $570 \mathrm{~nm}$ by using a spectrophotometer (SpectraMax 340PC ${ }^{384}$, Molecular Devices, Sunnyvale, CA, USA).

\subsection{Nitric Oxide Assay}

RAW 264.7 cells at a density of $3 \times 10^{4}$ cells/well were planted in a 24-well plate and preincubated with CS/F NPs and/or LPS for $24 \mathrm{~h}$. Subsequently, $50 \mu \mathrm{L}$ of $1 \%$ sulfanilamide was added to $100 \mu \mathrm{L}$ of supernatant for $10 \mathrm{~min}$ before adding $50 \mu \mathrm{L}$ of $0.1 \% \mathrm{~N}$-(1-naphthyl)-ethylenediamine dihydrochloride for another $10 \mathrm{~min}$. The absorbance of the product dye was measured at $540 \mathrm{~nm}$ by using a spectrophotometer (SpectraMax 340 $\mathrm{PC}^{384}$, Molecular Devices, Sunnyvale, CA, USA).

\subsection{Interleukin-6 Assay}

RAW 264.7 cells $\left(3 \times 10^{4}\right.$ cells/well) were planted in a 24 -well plate and preincubated with CS/F NPs and LPS for $24 \mathrm{~h}$. Subsequently, $100 \mu \mathrm{L}$ of supernatant were extracted to quantify interleukin-6 (IL-6), a proinflammatory mediator, using an enzyme-linked immunosorbent assay (ELISA). LPS was used as a positive control to stimulate the IL- 6 and validate the ELISA protocol. The principle of the ELISA is based on the sandwich technique. ELISA plates (NUNC, Polylabo, Strasbourg, France) were coated with capture antibodies $(200 \mathrm{ng} / \mathrm{mL})$ and blocked using bovine serum albumin $(1 \% \mathrm{w} / \mathrm{v})$ for $2 \mathrm{~h}$ at room temperature. After the $100 \mu \mathrm{L}$ diluted samples were added to the ELISA plates, a secondary antibody was added to the 96-well ELISA plate at a concentration of $250 \mathrm{ng} / \mathrm{mL}$, and the plates were incubated at room temperature for $2 \mathrm{~h}$. Streptavidin-conjugated horseradish peroxidase was then added to the plates. The substrate solution was subsequently added and the solution obtained thereby was incubated for $20 \mathrm{~min}$. The enzyme reaction was terminated with the addition of a $2 \mathrm{~N} \mathrm{H}_{2} \mathrm{SO}_{4}$ solution. The absorbance of the samples was read at $450 \mathrm{~nm}$ using an ELISA plate reader (SpectraMax $340 \mathrm{PC}^{384}$, Molecular Devices, Sunnyvale, CA, USA).

\subsection{MTT Assay}

Cell viability was measured using an MTT (3-(4,5-dimethylthiazol-2-yl)-2,5-diphenyltetrazolium bromide) assay (Sigma-Aldrich, St. Louis, MO, USA) according to manufacturer instructions. The A549 cells $\left(1.0 \times 10^{4}\right.$ cells/well $)$ were planted in 96-well plates and allowed to attach for $24 \mathrm{~h}$ before exposure to CS/F NPs solutions for another $24 \mathrm{~h}$. The MTT $(0.5 \mathrm{mg} / \mathrm{mL})$ was then added to each well and incubated at $37^{\circ} \mathrm{C}$ for $4 \mathrm{~h}$. After cautiously aspirating the culture medium, $1 \mathrm{~mL}$ of dimethyl sulfoxide (DMSO) was added and thoroughly mixed for $10 \mathrm{~min}$. Absorbance was determined at 570 and $630 \mathrm{~nm}$ (SpectraMax 340PC ${ }^{384}$, Molecular Devices, Sunnyvale, CA, USA). Cells grown without NPs were used as the control. Cell viability was expressed as a percentage of that observed in the control specimens. 


\subsection{Preparation of GM-Loaded CS/F NPs and in Vitro Release}

For preparing GM-loaded CS/F NPs, $200 \mu \mathrm{L}$ CS/acetic acid solution $(15 \mathrm{mg} / \mathrm{mL}, 20 \mathrm{mg} / \mathrm{mL}$ and $25 \mathrm{mg} / \mathrm{mL}$ ) was mixed homogeneously with a $200 \mu \mathrm{L} 1 \mathrm{mg} / \mathrm{mL}$ GM solution. Aqueous fucoidan solution $(5 \mathrm{mg} / \mathrm{mL})$ were then added to the CS/GM mixture by flush mixing, using a pipette tip under ultrasonic vibration at ice bath. Next, the prepared NPs were collected by centrifugation at 14,000 rpm for $5 \mathrm{~min}$. The NPs were then lyophilized or resuspended in phosphate buffered saline for further study.

In the release studies, GM was released from CS/F NPs. The prepared GM-loaded CS/F NPs were suspended in $1 \mathrm{~mL}$ of phosphate-buffered saline (PBS) and then incubated at $37{ }^{\circ} \mathrm{C}$ with agitation (100 r.p.m., Distek-2230A, North Brunswick, NJ, USA). At specified intervals, $500 \mu \mathrm{L}$ supernatant of sample was extracted and the solution was replenished with fresh buffer. The amount of GM in the supernatant was quantified by an indirect spectrophotometric method, using $o$-phtaldialdehyde as derivatizing agent [54]. The procedure is as follows. After dissolving $0.25 \mathrm{~g} o$-phtaldialdehyde in a mixture of methanol $(6.25 \mathrm{~mL})$ and 2-mercaptoethanol $(0.3 \mathrm{~mL})$, the resulting solution was mixed with $0.04 \mathrm{M}$ sodium borate $(56 \mathrm{~mL}, \mathrm{pH} 8)$ solution. For the colorimetric measurement, GM solution, $o$-phtaldialdehyde reagent and isopropanol were mixed in an equal volume ratio, and incubated for $30 \mathrm{~min}$ at room temperature. The absorbance of the samples was read at $340 \mathrm{~nm}$ using a spectrophotometer (SpectraMax 340PC ${ }^{384}$, Molecular Devices, Sunnyvale, CA, USA). The amount of GM was determined from a calibration curve based on known concentrations of GM.

\subsection{Statistical Analysis}

All quantitative data were expressed as mean \pm standard deviation (SD). A one-way ANOVA and post test statistical analyses were performed using GraphPad Prism 5. A $p$ value of $<0.05$ indicated statistical significance.

\section{Conclusions}

To achieve a sustained local effect of a drug in the lungs, developing a carrier with excellent biocompatibility, biodegradability, antioxidant activity and no inflammatory response is crucial when frequent administration is necessary. In addition, the carriers must be able to prevent mucociliary clearance and phagocytic mechanisms. To address this challenge, we developed a novel CS/F NP and evaluated its potency for a pulmonary delivery system. The prepared CS/F NPs were formed by electrostatic interaction and proved stable in phosphate-buffered saline ( $\mathrm{pH}$ 6.0-7.4). The physicochemical properties of CS/F NPs, such as size, zeta potential, and stability, depend on the weight ratio of chitosan to fucoidan. In the in vitro tests conducted in this study, the CS/F NPs exerted no cytotoxic effects on the A549 cells, as the concentration of NPs was between $0.375 \mathrm{mg} / \mathrm{mL}$ and $3 \mathrm{mg} / \mathrm{mL}$. The CS/F NPs exhibited scavenging effects and antioxidant activities according to the DPPH assay and ROS determination tests. Furthermore, undesirable inflammatory reactions were not induced. The CS/F NPs controlled the release of GM with an initial burst effect followed by a slow drug release. Overall, the experimental results indicate promising features of CS/F NPs for use in a pulmonary drug delivery system. 


\section{Acknowledgments}

The authors would like to thank the National Science Council of Taiwan for financially supporting this research under Contract No. NSC 102-2221-E-019-004. Thanks to Ms. C.-Y. Chien of Ministry of Science and Technology for the assistance in TEM experiments. Wallace Academic Editing is appreciated for editorial assistance.

\section{Author Contributions}

Conceived and designed the experiments: Yi-Cheng Huang. Performed the experiments: Rou-Ying Li. Analyzed the data: Yi-Cheng Huang and Rou-Ying Li. Wrote the paper: Yi-Cheng Huang.

\section{Conflicts of Interest}

The authors declare no conflict of interest.

\section{References}

1. Westerman, E.M.; de Boer, A.H.; le Brun, P.P.; Touw, D.J.; Roldaan, A.C.; Frijlink, H.W.; Heijerman, H.G. Dry powder inhalation of colistin in cystic fibrosis patients: A single dose pilot study. J. Cyst. Fibros. 2007, 6, 284-292.

2. Richardson, C.H.; de Matas, M.; Hosker, H.; Mukherjee, R.; Wong, I.; Chrystyn, H. Determination of the relative bioavailability of salbutamol to the lungs following inhalation from dry powder inhaler formulations containing drug substance manufactured by supercritical fluids and micronization. Pharm. Res. 2007, 24, 2008-2017.

3. Beaulac, C.; Sachetelli, S.; Lagace, J. Aerosolization of low phase transition temperature liposomal tobramycin as a dry powder in an animal model of chronic pulmonary infection caused by Pseudomonas aeruginosa. J. Drug Target 1999, 7, 33-41.

4. Evgenov, O.V.; Kohane, D.S.; Bloch, K.D.; Stasch, J.P.; Volpato, G.P.; Bellas, E.; Evgenov, N.V.; Buys, E.S.; Gnoth, M.J.; Graveline, A.R.; et al. Inhaled agonists of soluble guanylate cyclase induce selective pulmonary vasodilation. Am. J. Respir. Crit. Care Med. 2007, 176, 1138-1145.

5. Azarmi, S.; Tao, X.; Chen, H.; Wang, Z.; Finlay, W.H.; Lobenberg, R.; Roa, W.H. Formulation and cytotoxicity of doxorubicin nanoparticles carried by dry powder aerosol particles. Int. J. Pharm. 2006, 319, 155-161.

6. Shoyele, S.A.; Cawthorne, S. Particle engineering techniques for inhaled biopharmaceuticals. Adv. Drug Deliv. Rev. 2006, 58, 1009-1029.

7. Yoo, D.; Guk, K.; Kim, H.; Khang, G.; Wu, D.; Lee, D. Antioxidant polymeric nanoparticles as novel therapeutics for airway inflammatory diseases. Int. J. Pharm. 2013, 450, 87-94.

8. Labiris, N.R.; Dolovich, M.B. Pulmonary drug delivery. Part II: The role of inhalant delivery devices and drug formulations in therapeutic effectiveness of aerosolized medications. $\mathrm{Br}$. $\mathrm{J}$. Clin. Pharmacol. 2003, 56, 600-612.

9. Makino, K.; Yamamoto, N.; Higuchi, K.; Harada, N.; Ohshima, H.; Terada, H. Phagocytic uptake of polystyrene microspheres by alveolar macrophages: Effects of the size and surface properties of the microspheres. Colloid Surf. B Biointerfaces 2003, 27, 33-39. 
10. Schurch, S.; Gehr, P.; Im Hof, V.; Geiser, M.; Green, F. Surfactant displaces particles toward the epithelium in airways and alveoli. Respir. Physiol. 1990, 80, 17-32.

11. Yang, L.; Luo, J.; Shi, S.; Zhang, Q.; Sun, X.; Zhang, Z.; Gong, T. Development of a pulmonary peptide delivery system using porous nanoparticle-aggregate particles for systemic application. Int. J. Pharm. 2013, 451, 104-111.

12. Yang, X.; Liu, Y.; Liu, C.; Zhang, N. Biodegradable solid lipid nanoparticle flocculates for pulmonary delivery of insulin. J. Biomed. Nanotechnol. 2012, 8, 834-842.

13. Chattopadhyay, S. Aerosol generation using nanometer liposome suspensions for pulmonary drug delivery applications. J. Liposome Res. 2013, 23, 255-267.

14. Dokka, S.; Toledo, D.; Shi, X.; Castranova, V.; Rojanasakul, Y. Oxygen radical-mediated pulmonary toxicity induced by some cationic liposomes. Pharm. Res. 2000, 17, 521-525.

15. Dailey, L.A.; Schmehl, T.; Gessler, T.; Wittmar, M.; Grimminger, F.; Seeger, W.; Kissel, T. Nebulization of biodegradable nanoparticles: Impact of nebulizer technology and nanoparticle characteristics on aerosol features. J. Control. Release 2003, 86, 131-144.

16. Dailey, L.A.; Kleemann, E.; Wittmar, M.; Gessler, T.; Schmehl, T.; Roberts, C.; Seeger, W.; Kissel, T. Surfactant-free, biodegradable nanoparticles for aerosol therapy based on the branched polyesters, DEAPA-PVAL-g-PLGA. Pharm. Res. 2003, 20, 2011-2020.

17. Dailey, L.A.; Jekel, N.; Fink, L.; Gessler, T.; Schmehl, T.; Wittmar, M.; Kissel, T.; Seeger, W. Investigation of the proinflammatory potential of biodegradable nanoparticle drug delivery systems in the lung. Toxicol. Appl. Pharmacol. 2006, 215, 100-108.

18. Fiore, V.F.; Lofton, M.C.; Roser-Page, S.; Yang, S.C.; Roman, J.; Murthy, N.; Barker, T.H. Polyketal microparticles for therapeutic delivery to the lung. Biomaterials 2010, 31, 810-817.

19. Huang, Y.C.; Liu, T.J. Mobilization of mesenchymal stem cells by stromal cell-derived factor-1 released from chitosan/tripolyphosphate/fucoidan nanoparticles. Acta Biomater. 2012, 8, 1048-1056.

20. Huang, Y.C.; Yang, Y.T. Effect of basic fibroblast growth factor released from chitosan-fucoidan nanoparticles on neurite extension. J. Tissue Eng. Regen Med. 2013, doi:10.1002/term.1752.

21. Nishino, T.; Yokoyama, G.; Dobashi, K.; Fujihara, M.; Nagumo, T. Isolation, purification, and characterization of fucose-containing sulfated polysaccharides from the brown seaweed Ecklonia kurome and their blood-anticoagulant activities. Carbohydr. Res. 1989, 186, 119-129.

22. Chizhov, A.O.; Dell, A.; Morris, H.R.; Haslam, S.M.; McDowell, R.A.; Shashkov, A.S.; Nifant'ev, N.E.; Khatuntseva, E.A.; Usov, A.I. A study of fucoidan from the brown seaweed Chorda filum. Carbohydr. Res. 1999, 320, 108-119.

23. Cui, Y.Q.; Luo, D.Z.; Wang, X.M. Fucoidan: Advances in the study of its anti-inflammatory and anti-oxidative effects. Yao Xue Xue Bao 2008, 43, 1186-1189.

24. Berteau, O.; Mulloy, B. Sulfated fucans, fresh perspectives: Structures, functions, and biological properties of sulfated fucans and an overview of enzymes active toward this class of polysaccharide. Glycobiology 2003, 13, 29R-40R.

25. Rocha de Souza, M.C.; Marques, C.T.; Guerra Dore, C.M.; Ferreira da Silva, F.R.; Oliveira Rocha, H.A.; Leite, E.L. Antioxidant activities of sulfated polysaccharides from brown and red seaweeds. J. Appl. Phycol. 2007, 19, 153-160. 
26. Maruyama, H.; Tamauchi, H.; Hashimoto, M.; Nakano, T. Suppression of Th2 immune responses by mekabu fucoidan from Undaria pinnatifida sporophylls. Int. Arch. Allergy Immunol. 2005, 137, 289-294.

27. Yuan, Q.; Shah, J.; Hein, S.; Misra, R.D. Controlled and extended drug release behavior of chitosan-based nanoparticle carrier. Acta Biomater. 2010, 6, 1140-1148.

28. Das, S.; Chaudhury, A.; Ng, K.Y. Preparation and evaluation of zinc-pectin-chitosan composite particles for drug delivery to the colon: Role of chitosan in modifying in vitro and in vivo drug release. Int. J. Pharm. 2011, 406, 11-20.

29. Muzzarelli, R.A. Human enzymatic activities related to the therapeutic administration of chitin derivatives. Cell Mol. Life Sci. 1997, 53, 131-140.

30. Malaekeh-Nikouei, B.; Sajadi Tabassi, S.A.; Jaafari, M.R. Preparation, characterization, and mucoadhesive properties of chitosan-coated microspheres encapsulated with cyclosporine A. Drug Dev. Ind. Pharm. 2008, 34, 492-498.

31. De Campos, A.M.; Sanchez, A.; Alonso, M.J. Chitosan nanoparticles: A new vehicle for the improvement of the delivery of drugs to the ocular surface. Application to cyclosporin A. Int. J. Pharm. 2001, 224, 159-168.

32. Portero, A.; Remunan-Lopez, C.; Nielsen, H.M. The potential of chitosan in enhancing peptide and protein absorption across the TR146 cell culture model-an in vitro model of the buccal epithelium. Pharm. Res. 2002, 19, 169-174.

33. Artursson, P.; Lindmark, T.; Davis, S.S.; Illum, L. Effect of chitosan on the permeability of monolayers of intestinal epithelial cells (Caco-2). Pharm. Res. 1994, 11, 1358-1361.

34. Fernandez-Urrusuno, R.; Calvo, P.; Remunan-Lopez, C.; Vila-Jato, J.L.; Alonso, M.J. Enhancement of nasal absorption of insulin using chitosan nanoparticles. Pharm. Res. 1999, 16, 1576-1581.

35. Bandi, N.; Wei, W.; Roberts, C.B.; Kotra, L.P.; Kompella, U.B. Preparation of budesonide- and indomethacin-hydroxypropyl-beta-cyclodextrin (HPBCD) complexes using a single-step, organic-solvent-free supercritical fluid process. Eur. J. Pharm. Sci. 2004, 23, 159-168.

36. Tang, D.W.; Yu, S.H.; Ho, Y.C.; Mi, F.L.; Kuo, P.L.; Sung, H.W. Heparinized chitosan/ poly(gamma-glutamic acid) nanoparticles for multi-functional delivery of fibroblast growth factor and heparin. Biomaterials 2010, 31, 9320-9332.

37. Ungaro, F.; d'Angelo, I.; Coletta, C.; d'Emmanuele di Villa Bianca, R.; Sorrentino, R.; Perfetto, B.; Tufano, M.A.; Miro, A.; la Rotonda, M.I.; Quaglia, F. Dry powders based on PLGA nanoparticles for pulmonary delivery of antibiotics: Modulation of encapsulation efficiency, release rate and lung deposition pattern by hydrophilic polymers. J. Control. Release 2012, 157, 149-159.

38. Ozbas-Turan, S.; Akbuga, J.; Sezer, A.D. Topical application of antisense oligonucleotide-loaded chitosan nanoparticles to rats. Oligonucleotides 2010, 20, 147-153.

39. Sezer, A.D.; Akbuga, J. Comparison on in vitro characterization of fucospheres and chitosan microspheres encapsulated plasmid DNA (pGM-CSF): Formulation design and release characteristics. AAPS PharmSciTech 2009, 10, 1193-1199.

40. Yu, D.W.; Yang, T.; Sonoda, T.; Gong, Y.; Cao, Q.; Gaffney, K.; Jensen, P.J.; Freedberg, I.M.; Lavker, R.M.; Sun, T.T. Osteopontin gene is expressed in the dermal papilla of pelage follicles in a hair-cycle-dependent manner. J. Investig. Dermatol. 2001, 117, 1554-1558. 
41. Sanders, N.N.; de Smedt, S.C.; Demeester, J. The physical properties of biogels and their permeability for macromolecular drugs and colloidal drug carriers. J. Pharm. Sci. 2000, 89, 835-849.

42. Lieu, D.K.; Degraffenried, L.A.; Isseroff, R.R.; Kurzrock, E.A. Beta1 integrin expression pattern in transitional urothelium does not allow for efficient stem cell enrichment as in other epithelia. Tissue Eng. 2007, 13, 263-270.

43. Jarmila, V.; Vavrikova, E. Chitosan derivatives with antimicrobial, antitumour and antioxidant activities-A review. Curr. Pharm. Des. 2011, 17, 3596-3607.

44. Ruperez, P.; Ahrazem, O.; Leal, J.A. Potential antioxidant capacity of sulfated polysaccharides from the edible marine brown seaweed Fucus vesiculosus. J. Agric. Food Chem. 2002, 50, 840-845.

45. Lee, S.Y.; Cho, J.Y. Inhibitory effects of honokiol on LPS and PMA-induced cellular responses of macrophages and monocytes. BMB Rep. 2009, 42, 574-579.

46. Ji, J.G.; Hao, S.L.; Wu, D.J.; Huang, R.; Xu, Y. Preparation, characterization and in vitro release of chitosan nanoparticles loaded with gentamicin and salicylic acid. Carbohydr. Polym. 2011, 85, 803-808.

47. Achour, O.; Bridiau, N.; Godhbani, A.; le Joubioux, F.; Bordenave Juchereau, S.; Sannier, F.; Piot, J.M.; Fruitier Arnaudin, I.; Maugard, T. Ultrasonic-assisted preparation of a low molecular weight heparin (LMWH) with anticoagulant activity. Carbohydr. Polym. 2013, 97, 684-689.

48. Page, C. Heparin and related drugs: Beyond anticoagulant activity. ISRN Pharmacol. 2013, 2013, 910743.

49. Fermas, S.; Gonnet, F.; Sutton, A.; Charnaux, N.; Mulloy, B.; Du, Y.; Baleux, F.; Daniel, R. Sulfated oligosaccharides (heparin and fucoidan) binding and dimerization of stromal cell-derived factor-1 (SDF-1/CXCL 12) are coupled as evidenced by affinity CE-MS analysis. Glycobiology 2008, 18, 1054-1064.

50. Chabut, D.; Fischer, A.M.; Colliec-Jouault, S.; Laurendeau, I.; Matou, S.; le Bonniec, B.; Helley, D. Low molecular weight fucoidan and heparin enhance the basic fibroblast growth factor-induced tube formation of endothelial cells through heparan sulfate-dependent alpha6 overexpression. Mol. Pharmacol. 2003, 64, 696-702.

51. Kuno, T.; Naito, S.; Ito, H.; Ohta, M.; Kido, N.; Kato, N. Staining of the $O$-specific polysaccharide chains of lipopolysaccharides with alkaline bismuth. Microbiol. Immunol. 1986, $30,1207-1211$.

52. Nishio, K.; Horie, M.; Akazawa, Y.; Shichiri, M.; Iwahashi, H.; Hagihara, Y.; Yoshida, Y.; Niki, E. Attenuation of lipopolysaccharide (LPS)-induced cytotoxicity by tocopherols and tocotrienols. Redox Biol. 2013, 1, 97-103.

53. Kohroki, J.; Muto, N.; Tanaka, T.; Itoh, N.; Inada, A.; Tanaka, K. Induction of differentiation and apoptosis by dithizone in human myeloid leukemia cell lines. Leuk Res. 1998, 22, 405-412.

54. Frutos Cabanillas, P.; Diez Pena, E.; Barrales-Rienda, J.M.; Frutos, G. Validation and in vitro characterization of antibiotic-loaded bone cement release. Int. J. Pharm. 2000, 209, 15-26.

(C) 2014 by the authors; licensee MDPI, Basel, Switzerland. This article is an open access article distributed under the terms and conditions of the Creative Commons Attribution license (http://creativecommons.org/licenses/by/3.0/). 